Article

\title{
Improvement of a Specific Culture Medium Based on Industrial Glucose for Carotenoid Production by Xanthophyllomyces dendrorhous
}

\author{
Alejandro Torres-Haro (D), Anne Gschaedler, Juan C. Mateos-Díaz (D), Enrique J. Herrera-López (D), \\ Rosa M. Camacho-Ruíz (D) and Melchor Arellano-Plaza *(D)
}

check for updates

Citation: Torres-Haro, A.; Gschaedler, A.; Mateos-Díaz, J.C.; Herrera-López, E.J.; Camacho-Ruíz, R.M.; Arellano-Plaza, M. Improvement of a Specific Culture Medium Based on Industrial Glucose for Carotenoid Production by Xanthophyllomyces dendrorhous. Processes 2021, 9, 429. https:// doi.org/10.3390/pr9030429

Academic Editor: Joanna Berlowska

Received: 25 January 2021

Accepted: 22 February 2021

Published: 27 February 2021

Publisher's Note: MDPI stays neutral with regard to jurisdictional claims in published maps and institutional affiliations.

Copyright: (c) 2021 by the authors. Licensee MDPI, Basel, Switzerland. This article is an open access article distributed under the terms and conditions of the Creative Commons Attribution (CC BY) license (https:// creativecommons.org/licenses/by/ $4.0 /)$.
Industrial Biotechnology Laboratory, Centre for Research and Assistance in Technology and Design of Jalisco State A.C., Camino Arenero 1227, Col. El Bajío del Arenal, C.P. 45019 Zapopan, Jalisco, Mexico; altorres_al@ciatej.edu.mx (A.T.-H.); agschaedler@ciatej.mx (A.G.); jcmateos@ciatej.mx (J.C.M.-D.); eherrera@ciatej.mx (E.J.H.-L.); rcamacho@ciatej.mx (R.M.C.-R.)

* Correspondence: marellano@ciatej.mx; Tel.: +52-(33)-3345-5200

\begin{abstract}
In this study, a low-cost chemically defined (CD) culture medium was proposed and evaluated with the aim of replacing culture media such as yeast mold (YM) and yeast peptone dextrose (YPD), commonly used for growth and carotenoid production by Xanthophyllomyces dendrorhous. Initially, the CD culture medium was compared to the YM and YPD. The growth in optical density (OD) and carotenoid production (mg/L) of the cultures reached 4.88, 6.76, 5.79, and 0.67, 0.92, and 0.69, respectively. The $\mathrm{CD}$ culture served as the basis of an improved specific culture medium containing industrial glucose. Additionally, in this new formulation, vitamins, glutamate, and other compounds were evaluated. Industrial glucose more than doubled carotenoid production; however, the addition of vitamins was not essential for X. dendrorhous cultivation. Moreover, glutamate and $\mathrm{Na}_{2} \mathrm{HPO}_{4}$ proved to be highly significant factors ( $p$-value $<0.05$ ), increasing carotenoid biosynthesis from 0.67 to $1.33 \mathrm{mg} / \mathrm{L}$. The specific culture was successfully used in a bioreactor at $2 \mathrm{~L}$ and $110 \mathrm{~L}$ pilot-scale levels, increasing carotenoid production up to $2 \mathrm{mg} / \mathrm{L}$. It was demonstrated that the CD-specific culture medium is an efficient alternative to conventional culture media to carry out carotenoid production at the laboratory and pilot levels, with promising potential for industrial scaling.
\end{abstract}

Keywords: X. dendrorhous; carotenoids; chemical defined medium; industrial glucose; glutamate; vitamins

\section{Introduction}

Nowadays, carotenoids from natural sources have acquired importance in the market, mainly due to their diverse biological features such as the protective response caused by oxidative damage and their potential to act as a precursor to vitamin A formation. The most common carotenoids are lycopene, $\beta$-carotene, and astaxanthin, with the latter being of wide biotechnological interest [1]. Astaxanthin (3,3'-dihydroxy- $\beta, \beta^{\prime}$-carotene- $4,4^{\prime}$-dione) is a carotenoid pigment and powerful antioxidant belonging to the xanthophylls family. It is one of the main pigments available in marine environments, where it contributes to the color of crustacean shells, salmonid flesh, the feathers of some birds (flamingoes), and microalgae [2,3]. This compound has a hydrophobic character [4] and can be found naturally non-esterified or esterified with various fatty acids such as palmitic acid, stearic acid, or linoleic acid. The non-esterified form is commonly susceptible to oxidative degradation $[5,6]$.

Most commercial astaxanthin is produced by the petrochemical industry, generating annual sales above 200 million USD with a market cost of approximately 2500 USD/kg [7]. However, natural astaxanthin is preferred by consumers $[6,8,9]$ over the chemically synthesized type because it leads to unwanted by-products that can have harmful effects on human health [9]. Therefore, the search for natural alternative sources is of paramount 
interest for the food, pharmaceutical, and cosmetic industries. Microorganisms are a potential natural source of carotenoids, where the yeast Xanthophyllomyces dendrorhous and the microalgae Haematococcus pluvialis represent the principal astaxanthin producers [7,9-14].

Various studies have demonstrated that the production of carotenoids and astaxanthin using $X$. dendrorhous depends on the culture medium composition and the operational system conditions [14-20]; however, the high production costs limit the use of this yeast at an industrial level. Consequently, three approaches have been used to improve the yield and decrease production costs: (i) overproductive mutant strains, (ii) the implementation of fermentation systems providing higher productivities, and (iii) developing economical industrial culture media [14,19-23].

Regarding the use of culture media, yeasts require high assimilation nutrients such as glucose, nitrogen salts, and complex nutrients (yeast and/or malt extracts) $[10,14,15,18]$. The main complex culture media used in bioprocesses are yeast peptone dextrose (YPD), yeast complex (YC) [10], yeast mold (YM) [7,24], and others that use hydrolyzed substrates [20]. It has been found that operational conditions including a $\mathrm{pH}$ 6.0, temperature $20{ }^{\circ} \mathrm{C}[10,14-18,20,25,26]$, dissolved oxygen above $20 \%[15,20]$ and other factors such as white light $\left(177 \mu \mathrm{mol}\right.$ photon $\left./ \mathrm{m}^{2} \cdot \mathrm{s}^{1}\right)[7,25]$ and $5 \%-10 \%$ of inoculum [17] stimulate carotenoid biosynthesis by $X$. dendrorhous.

Liu and $\mathrm{Wu}$ [16] carried out a study through factorial design and response surface methodology to elucidate the optimal $\mathrm{pH}$ and carbon and nitrogen concentration sources in a complex culture medium to promote biomass growth and astaxanthin production using the overproducing strain ENM 5 of $X$. dendrorhous. It was found that glucose, $\left(\mathrm{NH}_{4}\right)_{2} \mathrm{SO}_{4}$, and $\mathrm{pH}$ were the main factors involved in astaxanthin production. The optimum biomass growth concentration was achieved with $34.3 \mathrm{~g} / \mathrm{L}$ of glucose, $2.95 \mathrm{~g} / \mathrm{L}$ of $\left(\mathrm{NH}_{4}\right)_{2} \mathrm{SO}_{4}$, and a $\mathrm{pH}$ of 5.85 , while the maximum carotenoid production of $9.5 \mathrm{mg} / \mathrm{L}$ was obtained with $19.3 \mathrm{~g} / \mathrm{L}$ of glucose, $0.81 \mathrm{~g} / \mathrm{L}$ of $\left(\mathrm{NH}_{4}\right)_{2} \mathrm{SO}_{4}$, and a $\mathrm{pH}$ of 5.19. Despite the optimum results being obtained, the effect of each nutrient on the biomass growth and carotenoid production is not evident due to the presence of yeast extract and corn liquor in the culture medium.

Pan et al. [27] evaluated the proteomic profile involved in astaxanthin biosynthesis in $X$. dendrorhous UV3-721, varying the $\mathrm{C} / \mathrm{N}$ ratio as a strategy to increase the compound production. It was found that a $\mathrm{C} / \mathrm{N}$ ratio of $76: 1$ in molar concentrations was a key factor in the production of astaxanthin in a culture medium of high complexity $(20 \mathrm{~g} / \mathrm{L}$ glucose, $0.2 \mathrm{~g} / \mathrm{L}$ yeast extract, $0.5 \mathrm{~g} / \mathrm{L}\left(\mathrm{NH}_{4}\right)_{2} \mathrm{SO}_{4}, 1.0 \mathrm{~g} / \mathrm{L} \mathrm{KH}_{2} \mathrm{PO}_{4}, 0.1 \mathrm{~g} / \mathrm{L} \mathrm{NaCl}, 0.5 \mathrm{~g} / \mathrm{L}$ $\mathrm{MgSO}_{4} \cdot 7 \mathrm{H}_{2} \mathrm{O}$, and $\left.0.1 \mathrm{~g} / \mathrm{L} \mathrm{CaCl}_{2} \cdot 2 \mathrm{H}_{2} \mathrm{O}\right)$. A high carbon ratio severely affects production yields due to a decrease in microbial growth [27], which can be a drawback in the scaling-up of the fermentation process.

Other studies carried out to date have attempted to maximize carotenoid production by applying inducers to stimulate biosynthesis. Wang et al. [19] evaluated mRNA expression levels and the protein expression and regulation occurring by feeding $0.368 \mathrm{~g} / \mathrm{L}$ of glutamate into a fermentative system as a mechanism of carotenoid accumulation and astaxanthin using a $\mathrm{C} / \mathrm{N}$ ratio of 76:1 molar. The production of astaxanthin increased by more than $40.7 \%$, reaching a concentration of $1.14 \mathrm{mg} / \mathrm{g}$ without having a significant effect on the production of biomass by X. dendrorhous UV3-72 in a culture medium of high complexity [27]. It was found that glutamate facilitates the assimilation of carbon and nitrogen sources present in the culture medium [19]. Consequently, it was deduced that glutamate is an important component in the formulation of a chemically defined culture medium, and for physiological and metabolic studies.

Complex culture media such as YM, YPD, and others $[16,19,27]$ are intended to promote growth and carotenoid production by $X$. dendrorhous. These culture media are based on yeast and/or malt extracts rich in nitrogen, vitamins, and ions; nevertheless, the concentration and type of micronutrients in each batch are unclear $[10,28,29]$. The vitamins are considered as relevant growth factors that play an important role in culture media formulation, and are needed in small quantities as metabolic precursors or coenzymes that allow various biochemical reactions [28]. Currently, due to the nutritional complexity of 
culture media, i.e., salts, glutamate, vitamins, minerals, etc., it is quite difficult to determine the effect of one or more specific nutrients in a defined concentration on the yeast growth and carotenoid production. Moreover, complex culture media have the disadvantage of not being practical for scaling to pilot and even industrial levels, due to the high costs that impact on the production of carotenoids by X. dendrorhous [20]. Therefore, it is imperative to develop and optimize low-cost culture media that employ specific substrates that interact in the metabolism of the yeast to increase the efficiency of the fermentative process.

In this study, the effects of certain nutrients on biomass growth and total carotenoid production were evaluated using the strain X. dendrorhous 25-2. For this purpose, a chemically defined (CD) culture medium containing nutrients such as vitamins (pantothenic acid, nicotinic acid, inositol, thiamine, pyridoxine, $p$-aminobenzoic acid, and biotin), glutamate, $\mathrm{KH}_{2} \mathrm{PO}_{4},\left(\mathrm{NH}_{4}\right)_{2} \mathrm{SO}_{4}$, and $\mathrm{Na}_{2} \mathrm{HPO}_{4}$ was developed. In addition, industrial glucose was tested as an alternative, low-cost carbon source for the expansion and improvement of carotenoid production at bioreactor levels (2 L and $110 \mathrm{~L}$ ), making it possible to employ this culture medium for scaling-up processes.

\section{Materials and Methods}

\subsection{Microorganism and Inoculum Activation}

In this study, the Xanthophyllomyces dendrorhous 25-2 strain was used, which was obtained by mutagenesis with nitrosoguanidine of a wild-type strain ATCC 24202 [17,30]. Strain 25-2 belongs to the collection of microorganisms of the Industrial Biotechnology Department of the Centre for Research and Assistance in Technology and Design of Jalisco State, A.C. (CIATEJ, AC).

The yeast was activated in a YM culture medium composed of $3.0 \mathrm{~g} / \mathrm{L}$ of yeast extract, $3.0 \mathrm{~g} / \mathrm{L}$ of malt extract, $5.0 \mathrm{~g} / \mathrm{L}$ of peptone, and $20 \mathrm{~g} / \mathrm{L}$ of glucose for $72 \mathrm{~h}$ at $20{ }^{\circ} \mathrm{C}$ and $250 \mathrm{rpm}$.

\subsection{Evaluation of the Low-Complexity CD Culture Medium at Shake Flask Level}

The total carotenoids and biomass produced by $X$. dendrorhous were evaluated using two complex culture media, YPD (10 g/L of yeast extract, $20 \mathrm{~g} / \mathrm{L}$ of peptone, and $20 \mathrm{~g} / \mathrm{L}$ of glucose) [10], and YM medium [28]. Afterwards, the CD culture medium was formulated $[12,26,30]$ and compared to the previous culture media; the assays were carried out in duplicate. We used 250-mL flasks with $50 \mathrm{~mL}$ of culture medium at $\mathrm{pH}$ 6.0, inoculated with $10 \%$ of the operation volume $[17,26]$ (approximately $5 \times 10^{6}$ cells $/ \mathrm{mL}$ ). The cultures were incubated in a New Brunswick ${ }^{\circledR}$ Innova 44 rotary orbital shaker (Hamburg, Germany) at $20^{\circ} \mathrm{C}$ and $250 \mathrm{rpm}[14-18,20]$.

The CD culture medium had the following composition $(\mathrm{g} / \mathrm{L}): \mathrm{KH}_{2} \mathrm{PO}_{4}, 3.0 ;\left(\mathrm{NH}_{4}\right)_{2} \mathrm{SO}_{4}$, 3.0; $\mathrm{Na}_{2} \mathrm{HPO}_{4} \cdot 12 \mathrm{H}_{2} \mathrm{O}$, 3.0; glutamic acid, 1.0; glucose, 20.0; $\mathrm{MgSO}_{4} \cdot 7 \mathrm{H}_{2} \mathrm{O}, 0.5 ; \mathrm{ZnSO}_{4} \cdot 7 \mathrm{H}_{2} \mathrm{O}$, 0.04; $\mathrm{MnSO}_{4} \cdot \mathrm{H}_{2} \mathrm{O}, 0.0038 ; \mathrm{CoCl}_{2} \cdot 6 \mathrm{H}_{2} \mathrm{O}, 0.0005 ; \mathrm{CuSO}_{4} \cdot 5 \mathrm{H}_{2} \mathrm{O}, 0.0009 ; \mathrm{Na}_{2} \mathrm{MoSO}_{4} \cdot 2 \mathrm{H}_{2} \mathrm{O}$, 0.00006; $\mathrm{CaCl}_{2} \cdot 2 \mathrm{H}_{2} \mathrm{O}, 0.023 ;\left(\mathrm{NH}_{4}\right)_{2} \mathrm{Fe}\left(\mathrm{SO}_{4}\right)_{2} \cdot 6 \mathrm{H}_{2} \mathrm{O}, 0.023 ; \mathrm{H}_{3} \mathrm{BO}_{3}, 0.003$; pantothenic acid, 0.005 ; nicotinic acid, 0.005 ; inositol, 0.125 ; thiamine 0.005 ; pyridoxine, 0.005 ; $p$-aminobenzoic acid, 0.001; and biotin, 0.000012 [23,30]. All of these compounds were obtained from SigmaAldrich $^{\mathrm{TM}}$ (San Luis, MI, USA).

\subsection{Impact of Vitamins on Carotenoid Production and Evaluation of an Industrial Carbon Source}

We studied the impact of $X$. dendrorhous on cell growth and carotenoid production when vitamins such as pantothenic acid, nicotinic acid, inositol, thiamine, pyridoxine, $p$-aminobenzoic acid, and biotin were added directly to the CD culture medium (highpurity glucose obtained from Sigma-Aldrich, Hamburg, Germany). Similarly, the absence of vitamins in the CD culture medium was also evaluated. Additionally, the addition of industrial glucose to previous assays was investigated as an alternative carbon source with the aim of replacing high-purity glucose; consequently, the presence/absence of vitamins was also evaluated in this culture medium. 
An initial experiment was carried out with the CD culture medium [30]. We used high-purity glucose (reagent grade), with or without vitamins, at $\mathrm{pH}$ 6.0. The results were compared to obtain specific information on the way these micronutrients impact on biomass growth and total carotenoid production. An additional experiment was carried out in which the $\mathrm{CD}$ culture medium was formulated using industrial-grade corn glucose as a carbon source (obtained from ALMEX, Guadalajara, Jalisco, Mexico) instead of highpurity glucose. The purpose of this formulation was to obtain a lower-cost culture medium for carotenoid production that can be scaled at pilot and industrial levels. The difference between the purity of the substrate and the carotenoid production was evaluated. The operational conditions used for this study are described in Section 2.2 and the inoculum used was previously activated in a CD culture medium for $72 \mathrm{~h}$ at $20^{\circ} \mathrm{C}$ and $250 \mathrm{rpm}$.

\subsection{Effect of the CD Culture Medium Macronutrients on Carotenoid and Biomass Production}

The efficiency of the $\mathrm{CD}$ culture medium for growth and total carotenoid production by X. dendrorhous was evaluated. A $2^{4}$ factorial design with two central points was carried out. The factors studied were the major components of the $\mathrm{CD}$ culture medium: glutamate $(1.0 \mathrm{~g} / \mathrm{L} ; 0.2 \mathrm{~g} / \mathrm{L}), \mathrm{KH}_{2} \mathrm{PO}_{4}$ (high level, $3.0 \mathrm{~g} / \mathrm{L}$; low level, $\left.0.5 \mathrm{~g} / \mathrm{L}\right), \mathrm{Na}_{2} \mathrm{HPO}_{4}(1.49 \mathrm{~g} / \mathrm{L}$; $0.5 \mathrm{~g} / \mathrm{L})$, and $\left(\mathrm{NH}_{4}\right)_{2} \mathrm{SO}_{4}(3.0 \mathrm{~g} / \mathrm{L} ; 0.5 \mathrm{~g} / \mathrm{L})$. The experiments were performed in duplicate for the different treatments (Table 1 ).

Table 1. Treatments performed to determine the effect of the main nutrients of the chemically defined (CD) culture medium on the X. dendrorhous strain 25-2.

\begin{tabular}{ccccc}
\hline Treatment & $\mathbf{K H}_{2} \mathbf{P O}_{\mathbf{4}}(\mathbf{g} / \mathrm{L})$ & $\mathbf{N a}_{2} \mathbf{H P O}_{\mathbf{4}} \mathbf{( g / L )}$ & $\begin{array}{c}\mathbf{N H}_{\mathbf{4}} \mathbf{~}_{\mathbf{2}} \mathbf{S O}_{\mathbf{4}} \\
\mathbf{( g / L )}\end{array}$ & $\begin{array}{c}\text { Glutamic Acid } \\
(\mathbf{g} / \mathbf{L})\end{array}$ \\
\hline 1 & 0.50 & 0.50 & 0.50 & 0.20 \\
2 & 3.00 & 0.50 & 0.50 & 0.20 \\
3 & 0.50 & 1.49 & 0.50 & 0.20 \\
4 & 3.00 & 1.49 & 0.50 & 0.20 \\
5 & 0.50 & 0.50 & 3.00 & 0.20 \\
6 & 3.00 & 0.50 & 3.00 & 0.20 \\
7 & 0.50 & 1.49 & 3.00 & 0.20 \\
8 & 3.00 & 1.49 & 3.00 & 1.00 \\
9 & 0.50 & 0.50 & 0.50 & 1.00 \\
10 & 3.00 & 0.50 & 0.50 & 1.00 \\
11 & 0.50 & 1.49 & 0.50 & 1.00 \\
12 & 3.00 & 1.49 & 0.50 & 1.00 \\
13 & 0.50 & 0.50 & 3.00 & 1.00 \\
14 & 3.00 & 0.50 & 3.00 & 1.00 \\
15 & 0.50 & 1.49 & 3.00 & 1.00 \\
16 & 3.00 & 1.49 & 3.00 & 0.73 \\
\end{tabular}

Treatment 16: High levels for all nutrients; Treatments 17 and 18: Central points of a $2^{4}$ factorial design.

\subsection{Carotenoid Production at the Bioreactor Level}

The industrial culture medium was evaluated at $2 \mathrm{~L}$ and $110 \mathrm{~L}$ levels in Applikon ${ }^{\circledR}$ bioreactors (Applikon Biotechnology, B.V., Delft, The Netherlands) using the specific nutrients required for carotenoid production by $X$. dendrorhous. The variables were controlled throughout the fermentation: $\mathrm{pH} 6.0$, at $20^{\circ} \mathrm{C}$, stirring speeds of $900 \mathrm{rpm}$ in the $2 \mathrm{~L}$ level and $500 \mathrm{rpm}$ in $110 \mathrm{~L}$ level, and aeration at $1 \mathrm{vvm}[21,26]$. The difference in stirring speeds between the fermentation systems is due to the $110 \mathrm{~L}$ bioreactor not having the ability to stir at the same speed as a $2 \mathrm{~L}$ system; however, due to their geometric designs, both are capable of supplying the oxygenation required under established conditions. The bioreactors were inoculated with $10 \%$ of the operation volume [17]. Figure 1 depicts a diagram of the general methodology used to carry out the present study. 


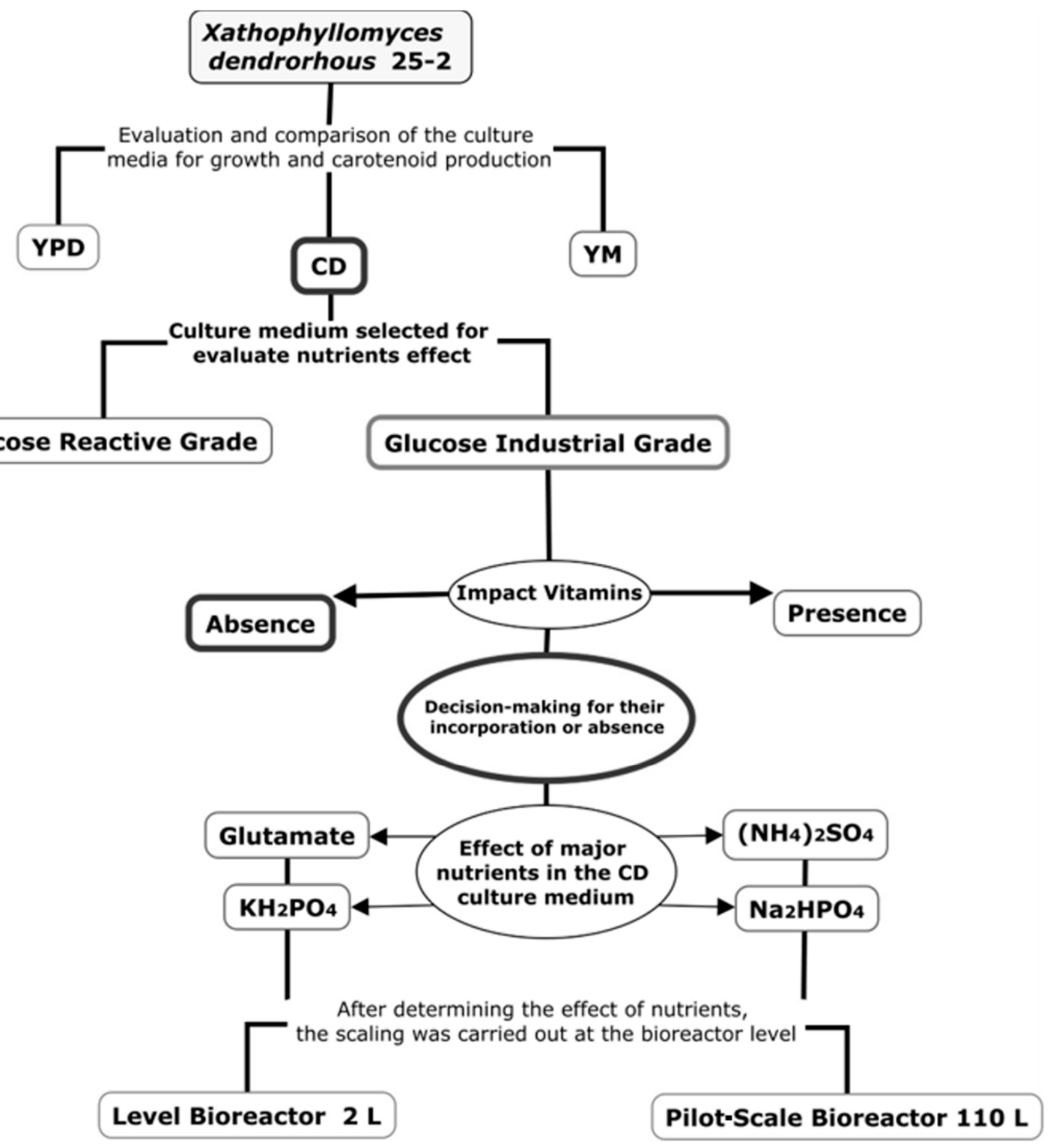

Figure 1. The methodological strategy used in this study.

\subsection{Analytical Techniques}

Biomass growth was determined by turbidimetry measurements at a wavelength of $600 \mathrm{~nm}$ in an xMark ${ }^{\mathrm{TM}}$ spectrophotometer (Bio-Rad Laboratories, Inc., Irvine, California, US), which reported these values as optical density (OD) units. Substrate consumption was evaluated by the dinitrosalicylic acid method [31]. The total carotenoid content was quantified using the methodology described by Sedmak et al. [32]. It was corroborated by high-performance liquid chromatography (HPLC), which showed that astaxanthin was the main carotenoid produced by the $X$. dendrorhous 25-2 strain used in the present study (Figure S1).

\subsection{Statistical Analysis}

STATGRAPHICS ${ }^{\circledR}$ software (Statgraphics Technologies, Inc., The Plains, VA, USA) was used to perform analysis of variance (ANOVA) and assess the surface response to determine significant factors or nutrients and their effects on carotenoid production by X. dendrorhous. 


\section{Results and Discussion}

\subsection{Evaluation of the Culture Media for Growth and Carotenoid Production}

In a first instance, shake flask fermentations were carried out to evaluate biomass growth and carotenoid production using complex culture media (YM and YPD), versus the low-complexity, formulated CD medium, which has minor and specific nutrients. The biomass growth, total carotenoid production, and substrate consumption were monitored for $108 \mathrm{~h}$. In the CD culture medium, we obtained $4.88 \mathrm{OD}$ units for biomass growth, while in the YM and YPD media we achieved 6.76 and 5.79 OD units, respectively (Figure 2). The cell growth in the CD culture medium decreased by $27.76 \pm 1.0 \%$ compared to YM. However, it is worth noting that the total carotenoid production and biomass growth in the three culture media did not show statistically significant differences ( $p$-value $<0.05)$. Substrates were depleted in all three culture media, where the consumption rate for YM was lower than that for the YPD and CD media. Despite the absence of malt and yeast extracts in the CD culture medium, it has the advantage of being assimilated (Figure 2). Malt and/or yeast extracts are mainly rich in nitrogen sources [33], hampering the assimilation of other nutrients.

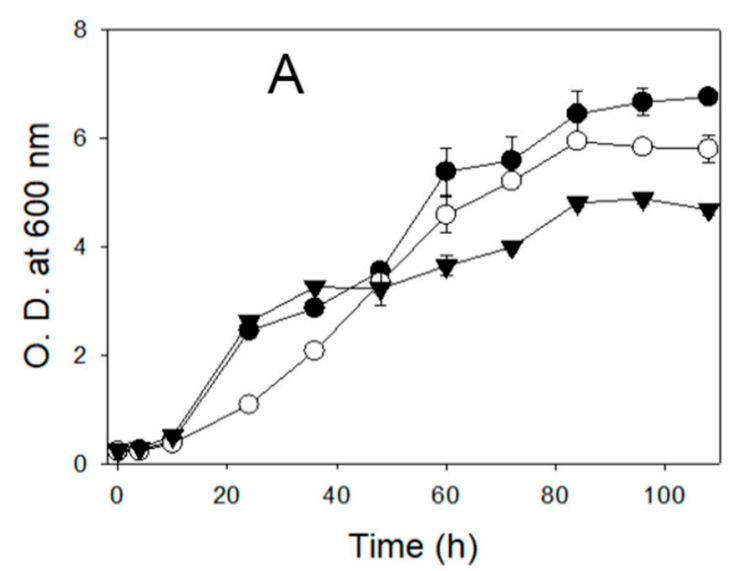

(A)

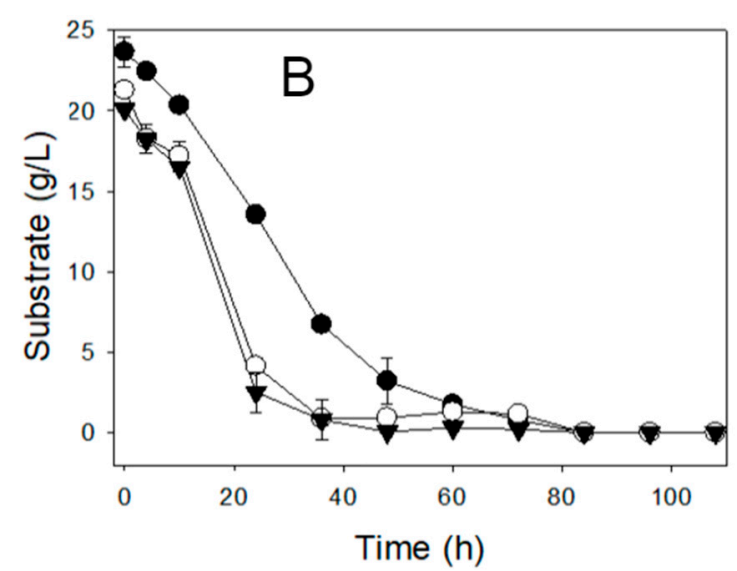

(B)

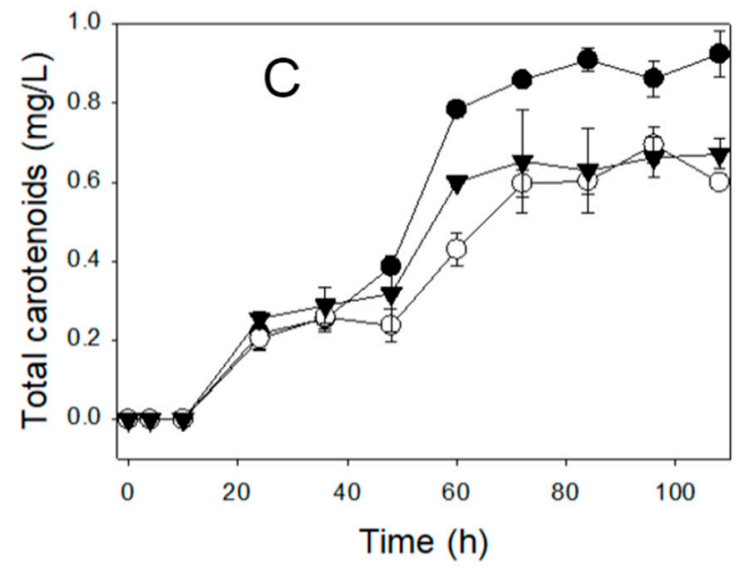

(C)

Figure 2. Culture media comparison for $(\mathbf{A})$ biomass growth, $(\mathbf{B})$ substrate consumption, and $(\mathbf{C})$ total carotenoid production by X. dendrorhous. (-○-) yeast peptone dextrose (YPD) culture medium, $(-\bullet-)$ yeast mold (YM) medium, and ( $-\mathbf{\nabla}-$ ) CD culture medium of low complexity.

Regarding total carotenoids (Figure 2), production was higher $(0.92 \mathrm{mg} / \mathrm{L})$ in the $\mathrm{YM}$ culture medium than in CD and YPD $(0.67$ and $0.69 \mathrm{mg} / \mathrm{L}$, respectively). The CD culture medium did not contain yeast or malt extract; however, the yeast was able to produce carotenoids at a similar level to that obtained in the YPD medium (complex culture medium; 
$p$-value $>0.05)$, demonstrating that the formulated culture medium contained enough nutrients to activate the carotenoids' metabolic pathway [30]. The YM culture medium contains malt extract, which is absent in the YPD culture medium. Malt extract has essential nutrients for growth and total carotenoid production by X. dendrorhous, thus, it plays an important role in the cultivation (effect shown in Figure 2), probably since similar nutrients such as vitamins, minerals, sugars, and high nitrogen concentrations [33] might be present in their natural habitat [34]. The CD culture medium also contained the nutrient sources present in the malt extract in chemically defined amounts, demonstrating that it is possible to use it to carry out physiological and metabolic studies [12,26,27,30], as well as to evaluate the impact of vitamins, glutamic acid, and other essential nutrients on biomass growth, and total carotenoid production.

\subsection{Impact of Vitamins on Growth and Carotenoid Production Using the CD Medium with Regent-Grade Glucose}

To elucidate the impact of vitamins on biomass growth and total carotenoid production, the $\mathrm{CD}$ culture medium was evaluated in the presence/absence of vitamins (see Section 2.3). A maximum biomass growth of 4.88 OD units was obtained in both assays, regardless of the presence or absence of vitamins ( $p$-value $>0.05)$. The results for the production of total carotenoids were similar, achieving a concentration of $0.67 \mathrm{mg} / \mathrm{L}$ with vitamins and $0.64 \mathrm{mg} / \mathrm{L}$ without them (Figure 3, Table 2). These results showed that the use of vitamins was not essential in the CD culture medium for growth and carotenoid production by X. dendrorhous.

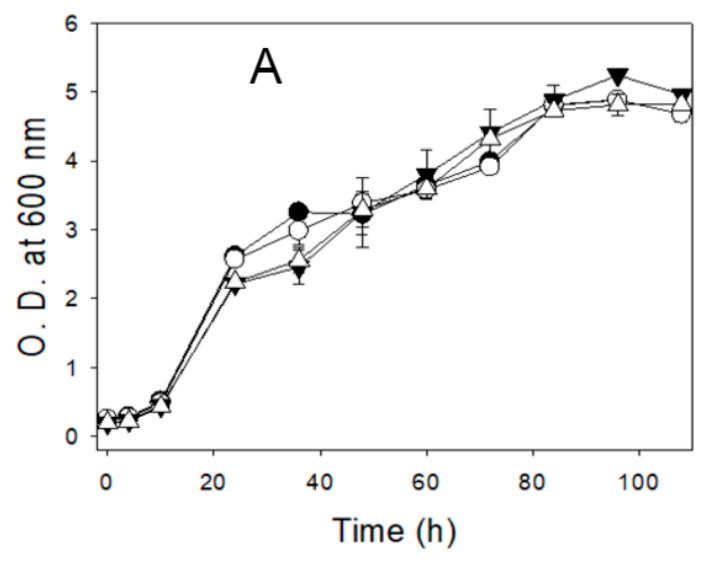

(A)

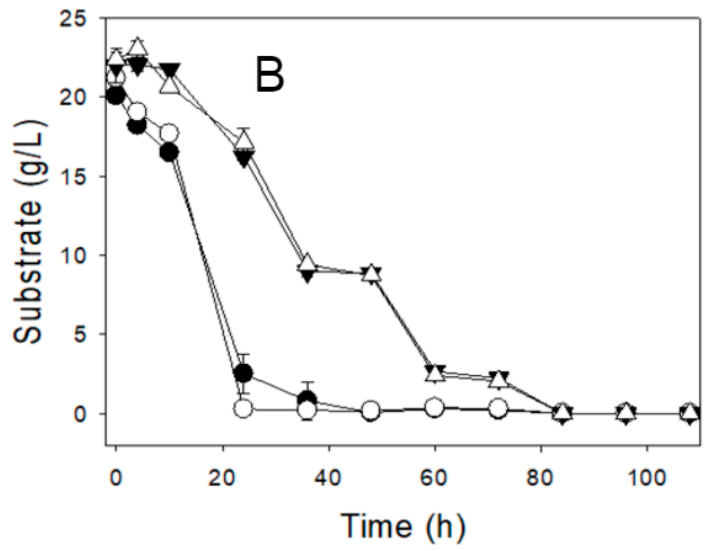

(B)

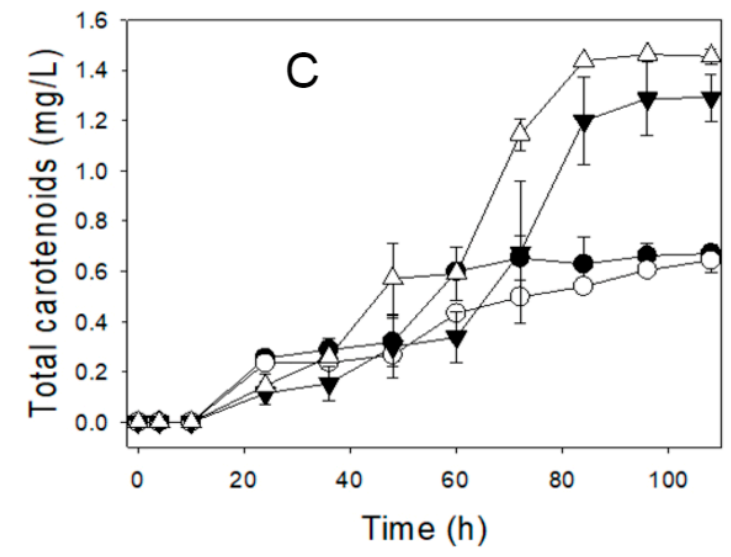

(C)

Figure 3. Effect of vitamins on CD culture medium with reactive-grade glucose (CDRG) and industrial-grade glucose (CDIG) for (A) the growth of biomass, (B) substrate consumption, and (C) total carotenoid production by X. dendrorhous. $(-\bullet-)$ CDRG medium with vitamins, $(-\bigcirc-)$ CDRG medium without vitamins, $(-\nabla-)$ CDIG medium with vitamins, and $(-\Delta-)$ CD culture medium. 
Table 2. Results of the evaluation of vitamins' impact on the carotenoid production and the glucose effect as a carbon source in X. dendrorhous.

\begin{tabular}{cccc}
\hline \multirow{2}{*}{ Carbon Source } & $\begin{array}{c}\text { Vitamins } \\
p \text {-Value }>\mathbf{0 . 0 5}\end{array}$ & OD600 nm & Carotenoids (mg/L) \\
\cline { 2 - 4 } & Present & $4.88 \pm 0.102$ & $0.67 \pm 0.038$ \\
\hline $\begin{array}{c}\text { Glucose, } \\
\text { reagent-grade }\end{array}$ & Absent & $4.88 \pm 0.127$ & $0.64 \pm 0.050$ \\
\cline { 2 - 4 } $\begin{array}{c}\text { Glucose, } \\
\text { industrial-grade }\end{array}$ & Present & $5.24 \pm 0.032$ & $1.29 \pm 0.092$ \\
\cline { 2 - 4 } & Absent & $4.82 \pm 0.021$ & $1.45 \pm 0.029$ \\
\hline
\end{tabular}

The vitamins serve as growth factors for microorganisms, which are needed in small quantities $\left(<1 \times 10^{-3} \mathrm{~g} / \mathrm{L}\right.$ of culture medium), and are used as coenzymes in metabolic processes [28]. The main vitamins are B complex such as thiamine (vitamin B1), pyridoxine (vitamin B6), and cobalamin (vitamin B12), which contribute to decarboxylation reactions and transacetylation, the transformation of amino acids, and keto acids, and the transfer of monocarbonate residues and deoxyribose synthesis, respectively. In addition, other important vitamins are pantothenic acid, a precursor of coenzyme A that activates acetyl groups; nicotinic acid, an NADH precursor for electron transfer in oxide reduction reactions; inositol, a precursor and messenger of fatty acids in membranes; $p$-aminobenzoic acid, a precursor of folic acid for carbon metabolism and the transfer of methyl groups; and biotin for the biosynthesis of fatty acids and decarboxylation [28].

It was expected that the addition of vitamins would have a positive effect, increasing the total carotenoid production, since vitamins are directly involved in the biosynthesis of precursor compounds $[28,35,36]$. However, the effects were not significant ( $p$-value $>0.05)$ since only a slight increase in carotenoids $(0.03 \mathrm{mg} / \mathrm{L})$ was observed. There were no considerable effects on growth and carotenoid production when vitamins were added to the $C D$ medium, probably because some microorganisms including the yeast $X$. dendrorhous have the ability to synthesize all the vitamins or coenzymes required for metabolic processes [28].

\subsection{Impact of Vitamins on Growth and Carotenoid Production Using the CD Medium with Industrial-Grade Glucose}

High-purity glucose (reagent-grade glucose) is a major component of the CD culture medium, which makes the medium more expensive. Therefore, we evaluated the impact of using an industrial-grade glucose as a carbon source and as a substitute for the reagentgrade glucose in the $\mathrm{CD}$ culture medium, while still maintaining the efficiency of the fermentation process in terms of the biomass growth and carotenoid production by $X$. dendrorhous. Furthermore, we evaluated the impact of the presence or absence of vitamins using this alternative carbon source.

Regarding the presence or absence of vitamins using industrial glucose as a carbon source, no significant impact on biomass growth and carotenoid production ( $p$-value $>0.05)$ was observed. The results are shown in Figure 3 and Table 2. However, using industrial glucose as a low-cost carbon source increased the total carotenoid production from 0.6 to $1.3 \pm 0.1 \mathrm{mg} / \mathrm{L}$, improving the efficiency of the process-with up to $54 \%$ more product compared to the use of reactive-grade glucose, denoting a significant difference (Table 2; $p$-value < 0.05). Industrial glucose is highly fermentable (Figure 3), of its total composition, $72.5 \%$ are carbohydrates, mainly as glucose $(85-86 \%)$, and it also contains maltose $(13.44 \%)$ and fructose $(0.08 \%)$ [ 15,37$]$, according to the specifications of the supplier. Probably, the presence of simple sugars (glucose and fructose) in conjunction with maltose, which are highly fermentable and assimilable, stimulates the production of carotenoids in the presence of glutamate, which is an inducer and activator of carbon, and nitrogen assimilation for the subsequent biosynthesis of carotenoids by X. dendrorhous [19]. The growth showed no significant difference ( $p$-value $>0.05$ ) in terms of biomass. 
Nangia et al. [38] evaluated the impact of different carbon sources (rice, cane juice, and sucrose) on the production of astaxanthin by yeast mutants of $X$. dendrorhous and compared the results against the production obtained when using dextrose as the main carbon source. The results showed yeast growth for all conditions, although the pigmentation varied from 1.5 to 2.5 OD units. Dextrose is used as a carbon source, as it is mainly assimilable for the production of biomass and astaxanthin, since it can be used directly in the metabolism of glycolysis, and through this route, in the biosynthesis of fatty acids and subsequently, the biosynthesis of carotenoids and astaxanthin $[39,40]$. However, glucose in excessive amounts has been reported to be a repressor of astaxanthin synthesis through the so-called Crabtree effect [41].

\subsection{Effect of Major Nutrients Contained in the CD Culture Medium on Growth (Kinetic Parameters) and Carotenoid Production}

A $2^{4}$ factorial design with central points was used to study the impact of the major nutrients in the $\mathrm{CD}$ culture medium on growth and carotenoid production, including glutamic acid, $\mathrm{KH}_{2} \mathrm{PO}_{4}, \mathrm{Na}_{2} \mathrm{HPO}_{4}$ and $\left(\mathrm{NH}_{4}\right)_{2} \mathrm{SO}_{4}$, using industrial-grade glucose as a carbon source without vitamins, since their addition did not lead to an increase in carotenoid production. The results obtained in this experiment are shown in Table 3. Due to the increase in product yields per substrate, the concentration of the carbon source was set to $15 \mathrm{~g} / \mathrm{L}$, since no significant difference in carotenoid production was observed when 15-20 g/L glucose was used. This can be explained because the carbon-nitrogen ratio is lower and the formation of carotenoids is induced by the metabolism of the Krebs cycle, which is stimulated by nitrogen [42-44].

Table 3. Cell growth, carotenoid production and kinetic parameters of a $2^{4}$ factorial design with two central points by $X$. dendrorhous 25-2.

\begin{tabular}{|c|c|c|c|c|c|c|c|}
\hline Treatment & $\begin{array}{l}\text { Cell Density } \\
\text { (OD600 nm) }\end{array}$ & $\begin{array}{l}\text { Carotenoids } \\
(\mathrm{mg} / \mathrm{L})\end{array}$ & $\begin{array}{c}\mathrm{Y}_{\mathrm{P} / \mathrm{X}} \\
(\mathrm{mg} / \mathrm{DO})\end{array}$ & $\begin{array}{c}\mathrm{Y}_{\mathrm{P} / \mathrm{S}} \\
(\mathrm{mg} / \mathrm{g})\end{array}$ & $\begin{array}{c}\mathrm{Y}_{\mathrm{X} / \mathrm{S}} \\
(\mathrm{DO} / \mathrm{g})\end{array}$ & $\begin{array}{c}\text { * Productivity } \\
(\mathrm{mg} / \mathrm{L} \cdot \mathrm{h})\end{array}$ & $\mathrm{C} / \mathrm{N}$ \\
\hline 1 & $2.54 \pm 0.75$ & $0.75 \pm 0.11$ & $0.293 \pm 0.13$ & $0.050 \pm 0.00$ & $0.170 \pm 0.05$ & 0.008 & 64.34 \\
\hline 2 & $3.77 \pm 0.43$ & $1.09 \pm 0.00$ & $0.288 \pm 0.03$ & $0.072 \pm 0.00$ & $0.251 \pm 0.03$ & 0.011 & 64.34 \\
\hline 3 & $3.09 \pm 0.94$ & $0.94 \pm 0.22$ & $0.303 \pm 0.02$ & $0.062 \pm 0.02$ & $0.206 \pm 0.06$ & 0.010 & 64.34 \\
\hline 4 & $3.94 \pm 0.03$ & $1.08 \pm 0.10$ & $0.274 \pm 0.02$ & $0.072 \pm 0.01$ & $0.262 \pm 0.00$ & 0.011 & 64.34 \\
\hline 5 & $2.95 \pm 0.75$ & $0.80 \pm 0.15$ & $0.269 \pm 0.02$ & $0.053 \pm 0.01$ & $0.197 \pm 0.05$ & 0.008 & 12.45 \\
\hline 6 & $3.51 \pm 0.62$ & $1.13 \pm 0.05$ & $0.321 \pm 0.04$ & $0.075 \pm 0.00$ & $0.234 \pm 0.04$ & 0.012 & 12.45 \\
\hline 7 & $3.26 \pm 0.68$ & $0.91 \pm 0.35$ & $0.278 \pm 0.05$ & $0.060 \pm 0.02$ & $0.217 \pm 0.04$ & 0.009 & 12.45 \\
\hline 8 & $3.76 \pm 0.22$ & $1.38 \pm 0.10$ & $0.368 \pm 0.05$ & $0.092 \pm 0.01$ & $0.250 \pm 0.01$ & 0.014 & 12.45 \\
\hline 9 & $3.73 \pm 0.18$ & $1.18 \pm 0.08$ & $0.316 \pm 0.00$ & $0.079 \pm 0.01$ & $0.249 \pm 0.01$ & 0.012 & 38.60 \\
\hline 10 & $4.14 \pm 0.29$ & $1.33 \pm 0.01$ & $0.320 \pm 0.01$ & $0.088 \pm 0.01$ & $0.276 \pm 0.02$ & 0.014 & 38.60 \\
\hline 11 & $3.90 \pm 0.11$ & $1.33 \pm 0.03$ & $0.341 \pm 0.02$ & $0.089 \pm 0.00$ & $0.260 \pm 0.01$ & 0.014 & 38.60 \\
\hline 12 & $4.26 \pm 0.28$ & $1.41 \pm 0.11$ & $0.331 \pm 0.01$ & $0.094 \pm 0.01$ & $0.284 \pm 0.02$ & 0.015 & 38.60 \\
\hline 13 & $3.31 \pm 0.99$ & $1.06 \pm 0.25$ & $0.321 \pm 0.02$ & $0.071 \pm 0.02$ & $0.220 \pm 0.07$ & 0.011 & 11.03 \\
\hline 14 & $3.96 \pm 0.32$ & $1.22 \pm 0.20$ & $0.307 \pm 0.03$ & $0.081 \pm 0.01$ & $0.264 \pm 0.02$ & 0.013 & 11.03 \\
\hline 15 & $3.52 \pm 0.69$ & $1.33 \pm 0.08$ & $0.378 \pm 0.10$ & $0.089 \pm 0.01$ & $0.235 \pm 0.04$ & 0.014 & 11.03 \\
\hline 16 & $3.20 \pm 0.64$ & $1.24 \pm 0.08$ & $0.388 \pm 0.05$ & $0.083 \pm 0.01$ & $0.213 \pm 0.04$ & 0.013 & 11.03 \\
\hline 17 & $3.72 \pm 0.82$ & $1.20 \pm 0.10$ & $0.323 \pm 0.05$ & $0.080 \pm 0.01$ & $0.248 \pm 0.05$ & 0.013 & 15.05 \\
\hline 18 & $2.95 \pm 1.20$ & $1.09 \pm 0.02$ & $0.368 \pm 0.18$ & $0.072 \pm 0.00$ & $0.196 \pm 0.08$ & 0.011 & 24.36 \\
\hline
\end{tabular}

$\mathrm{Y}_{\mathrm{P} / \mathrm{X}}$ : product per biomass yield; $\mathrm{Y}_{\mathrm{P} / \mathrm{S}}$ : product per substrate yield; $\mathrm{Y}_{\mathrm{X} / \mathrm{S}}$ : biomass per substrate yield. ${ }^{*}$ The standard deviation is not shown as it tends to be close to zero. Bold data means better results.

The results obtained show that, with $\mathrm{KH}_{2} \mathrm{PO}_{4}$ at the highest level, all response variables increased (Table 4, Figure 4). During treatment 1 (low levels of $\mathrm{KH}_{2} \mathrm{PO}_{4}$ ), carotenoids were obtained at a concentration of $0.75 \mathrm{mg} / \mathrm{L}$. However, treatment with a high level of $\mathrm{KH}_{2} \mathrm{PO}_{4}$ (treatment 2) led to an increase of $45.33 \% \pm 14.67 \%$ in the production of carotenoids; consequently, the potassium source showed a positive effect. Liu and Wu [16] found similar results for essential nutrients along with glucose in the culture medium, with $\mathrm{KH}_{2} \mathrm{PO}_{4}$ proving to be one of the most important factors in biomass and carotenoid 
production. The increase in biomass could be attributed to the potassium source $\left(\mathrm{KH}_{2} \mathrm{PO}_{4}\right)$, due to its important role within cellular functions as a protein precursor because it is an enzyme activator involved in protein synthesis for cell growth [28].

Table 4. $p$-Values obtained from the analysis of variance (ANOVA).

\begin{tabular}{ccccc}
\hline & \multicolumn{4}{c}{ Factor } \\
\cline { 2 - 5 } & $\mathbf{K H}_{\mathbf{2}} \mathbf{P O}_{\mathbf{4}}$ & $\mathbf{N a}_{\mathbf{2}} \mathbf{H} \mathbf{P O}_{\mathbf{4}}$ & $\mathbf{( N H}_{\mathbf{4}} \mathbf{~} \mathbf{2}_{\mathbf{2}} \mathbf{S O}_{\mathbf{4}}$ & Glutamic Acid \\
\hline Carotenoids & 0.0002 & 0.0076 & 0.9161 & 0.0000 \\
Biomass & 0.0164 & 0.5470 & 0.2630 & 0.0644 \\
${ }^{*} \mathrm{Y}_{\mathrm{X} / \mathrm{S}}$ & 0.0000 & 0.1286 & 0.0053 & 0.0000 \\
${ }^{*} \mathrm{Y}_{\mathrm{P} / \mathrm{S}}$ & 0.0000 & 0.0000 & 0.8670 & 0.0000 \\
\hline
\end{tabular}

${ }^{*} \mathrm{Y}_{\mathrm{X} / \mathrm{S}}$ : biomass per substrate yield $(\mathrm{DO} / \mathrm{g}) ;{ }^{*} \mathrm{Y}_{\mathrm{P} / \mathrm{S}}:$ product per substrate yield $(\mathrm{mg} / \mathrm{g})$.
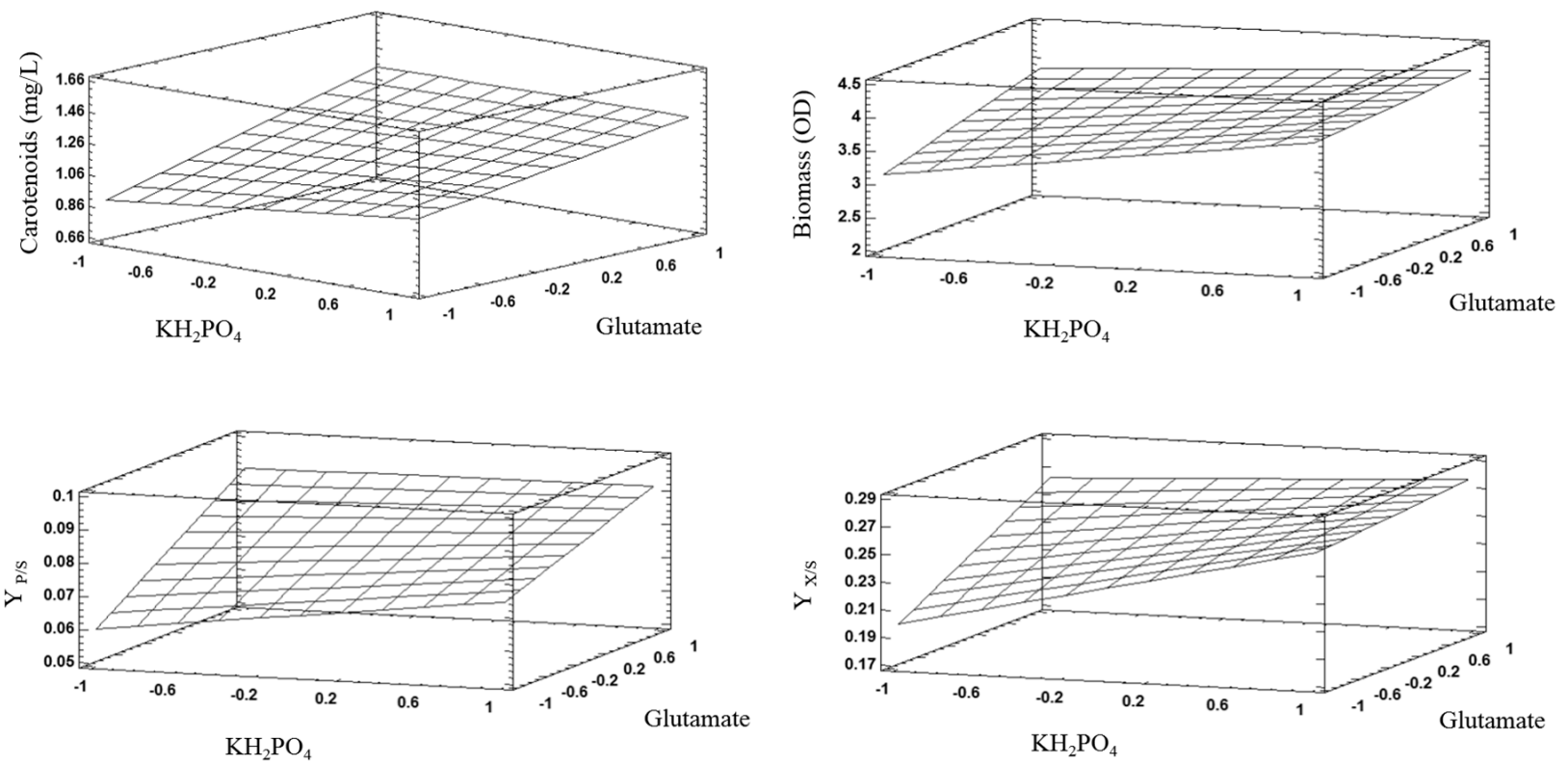

Figure 4. Response surfaces obtained for carotenoid production (mg/L), biomass production (OD), biomass yield per substrate: $\mathrm{Y}_{\mathrm{X} / \mathrm{S}}(\mathrm{g} / \mathrm{g})$, and product yield per substrate: $\mathrm{Y}_{\mathrm{P} / \mathrm{S}}(\mathrm{mg} / \mathrm{g})$, keeping $\mathrm{Na}_{2} \mathrm{HPO}_{4}$ at a high level and $\left(\mathrm{NH}_{4}\right)_{2} \mathrm{SO}_{4}$ at a low level.

$\mathrm{Na}_{2} \mathrm{HPO}_{4}$, which is used as a nutrient by some microorganisms [28], contributes to an increase in environmental stress and is necessary for carotenoid production [9]. Treatment 11, with a high level of $\mathrm{Na}_{2} \mathrm{HPO}_{4}$, showed a positive effect on carotenoid production (an increase of more than $11 \%$ ) compared with a low level of $\mathrm{Na}_{2} \mathrm{HPO}_{4}$ (treatment 9). Moreover, when $\mathrm{Na}_{2} \mathrm{HPO}_{4}$ was used at a high level in combination with glutamate, the highest astaxanthin production $(1.41 \mathrm{mg} / \mathrm{L})$ was obtained. According to the results described, $\mathrm{Na}_{2} \mathrm{HPO}_{4}$ had no significant influence in terms of biomass production; however, it was the component that contributed the most to carotenoid production. In addition, it was determined that this compound at high concentrations was an important factor in carotenoid production, as can be observed in the surface response (Figure 4).

Comparing treatments 1 and 5, with low and high levels of $\left(\mathrm{NH}_{4}\right)_{2} \mathrm{SO}_{4}$, we observed that carotenoid production increased by $0.05 \mathrm{mg} / \mathrm{L}$ in the high-level treatment. This compound is a nitrogen source used mainly for cell growth $[19,27,28]$. This effect was also observed when treatments 12 and 16 were compared at high and low levels of the nitrogen source, since it did not have a positive effect on the response variables of the experimental design, except on the biomass yield (Table 3); for this reason, $\left(\mathrm{NH}_{4}\right)_{2} \mathrm{SO}_{4}$ was maintained at its lower level in all the results for the surface response (Figure 4). Our results differ from those reported by Liu and $\mathrm{Wu}[16]$, who determined that this compound was a significant 
factor in carotenoid production. Other studies have also found that this factor is of vital importance for carotenoid biosynthesis on mutants of X. dendrorhous [45]. Similarly, a recent study conducted by Stoklosa et al. [46] determined that ammonium sulfate was an indispensable component in the presence of yeast extract and urea for high biomass and astaxanthin production by X. dendrorhous strain ATCC 74,219 (UBV-AX2), using sweet sorghum juice as the carbon source and obtaining yields above $36.6 \mathrm{~g} / \mathrm{L}$ of biomass and $65.8 \mathrm{mg} / \mathrm{L}$ of astaxanthin.

Finally, glutamate was the most important nutritional factor for carotenoid and astaxanthin production in the CD culture medium (Table 4, Figure 4). Glutamate had a more positive impact at higher concentrations than at lower levels, for instance, treatment 9 resulted in carotenoid overproduction by $57 \%$ compared to treatment 1 . These results can be attributed to the fact that glutamate plays an important role in cellular metabolism, where it mediates nitrogen and carbon assimilation $[47,48]$. Adding glutamate to the culture medium for the production of carotenoids using $X$. dendrorhous is a promising strategy to increase the yield, since this compound activates genes that facilitate the assimilation of glucose, decrease the generation of reactive oxygen species, increase the channels of isocitrate flow in the glyoxylate cycle, and participate in the cycle of the five-carbon compounds, promoting the accessibility of acetyl-CoA as a precursor for carotenoid biosynthesis and shifting the metabolic flow to obtain astaxanthin as the main product $[19,20,27]$.

Glutamate is a precursor of the synthesis of proteins, nucleic acids, and substrate gluconeogenesis, among other cellular metabolism compounds [28,49]. Furthermore, this important factor, along with $\mathrm{Na}_{2} \mathrm{HPO}_{4}$, resulted in an increase in carotenoid production when using high levels of these two factors and discarding $\mathrm{KH}_{2} \mathrm{PO}_{4}$ and $\left(\mathrm{NH}_{4}\right)_{2} \mathrm{SO}_{4}$ as nutrients, since use of these compounds showed no significant differences ( $p$-value $>0.05$ ) (Table 4).

Comparisons between treatments $8,9,11,12,15$, and 16, along with other media such as YM and YPD were evaluated (Figure 5). The highest level of carotenoid production was obtained in treatments 8 and 12, which required high concentrations of potassium, phosphate, sodium, and nitrogen (1.38 and $1.41 \mathrm{mg} / \mathrm{L}$, respectively). With treatments 9 and 11, carotenoid concentrations of 1.2 and $1.4 \mathrm{mg} / \mathrm{L}$ were obtained, respectively. These results were similar to treatments 8 and 12; however, low nutritional levels were required for treatments 9 and 11, i.e., limited potassium, phosphate, and nitrogen sources, except for glutamate, which is why they were selected to evaluate scaling at the bioreactor level. The results showed that the culture media developed in this study have the potential to compete against complex culture media to produce carotenoids by X. dendrorhous, at higher concentrations.

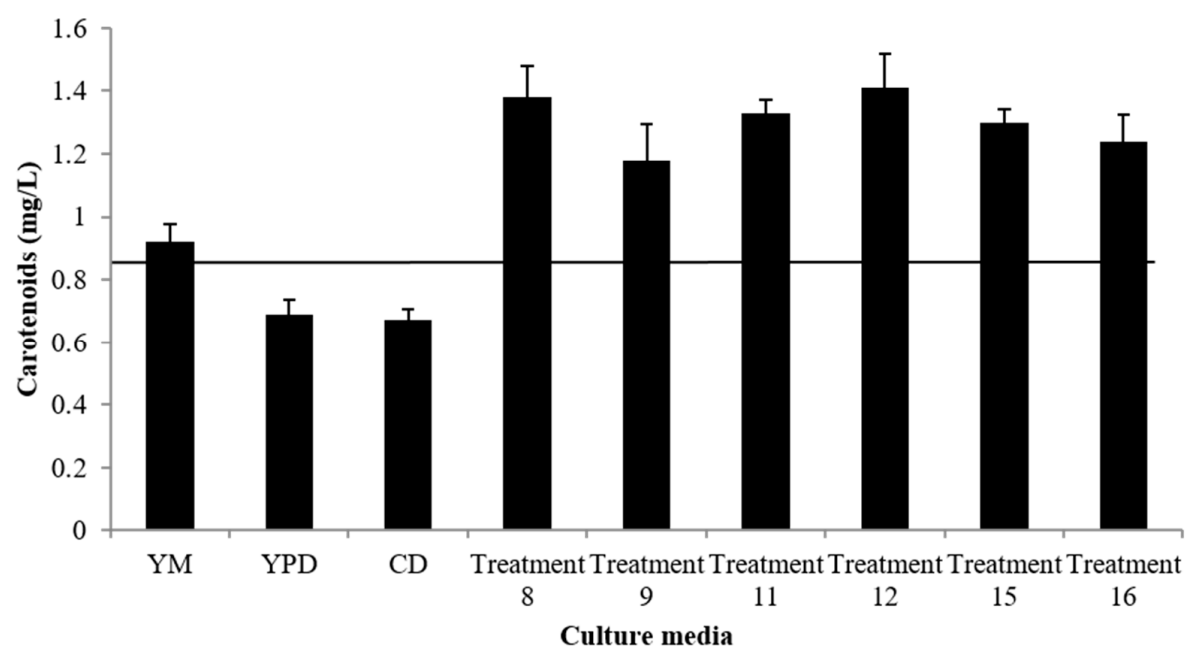

Figure 5. Comparisons of carotenoid production obtained with the complex culture media (YPD and YM) against the CD culture medium defined in this study. Production levels greater than $1 \mathrm{mg} / \mathrm{L}$ were considered significant for the strain 25-2 of X. dendrorhous. 


\subsection{Bioreactor Scale-Up of Carotenoid Production Using a Specific CD Culture Medium Based on Industrial Glucose}

Treatments 9 and 11 were selected for scale-up in a $2 \mathrm{~L}$ bioreactor, since these results showed higher carotenoid production than YM medium, with a production difference above $30 \%$. Results were compared with treatment 16 , which contained all nutrients at high concentrations (CD control medium) [25]. Figure 6 shows that carotenoid production was higher at the $2 \mathrm{~L}$ bioreactor level $(1.81 \mathrm{mg} / \mathrm{L}, 1.82 \mathrm{mg} / \mathrm{L}$, and $2.27 \mathrm{mg} / \mathrm{L}$ for treatments 16,9 , and 11, respectively) than in the shake flasks; this can be attributed to the control of operating conditions such as $\mathrm{pH}$ and aeration in the fermenter [50]. Aeration increased the oxygen transfer into the cells, having a positive effect on carotenoid production, since dissolved oxygen stimulates aerobic metabolism and oxidative stress $[15,19,28]$. Therefore, a defense response is generated, activating the carotenoids and astaxanthin biosynthesis to reduce cellular oxidation $[43,51]$.

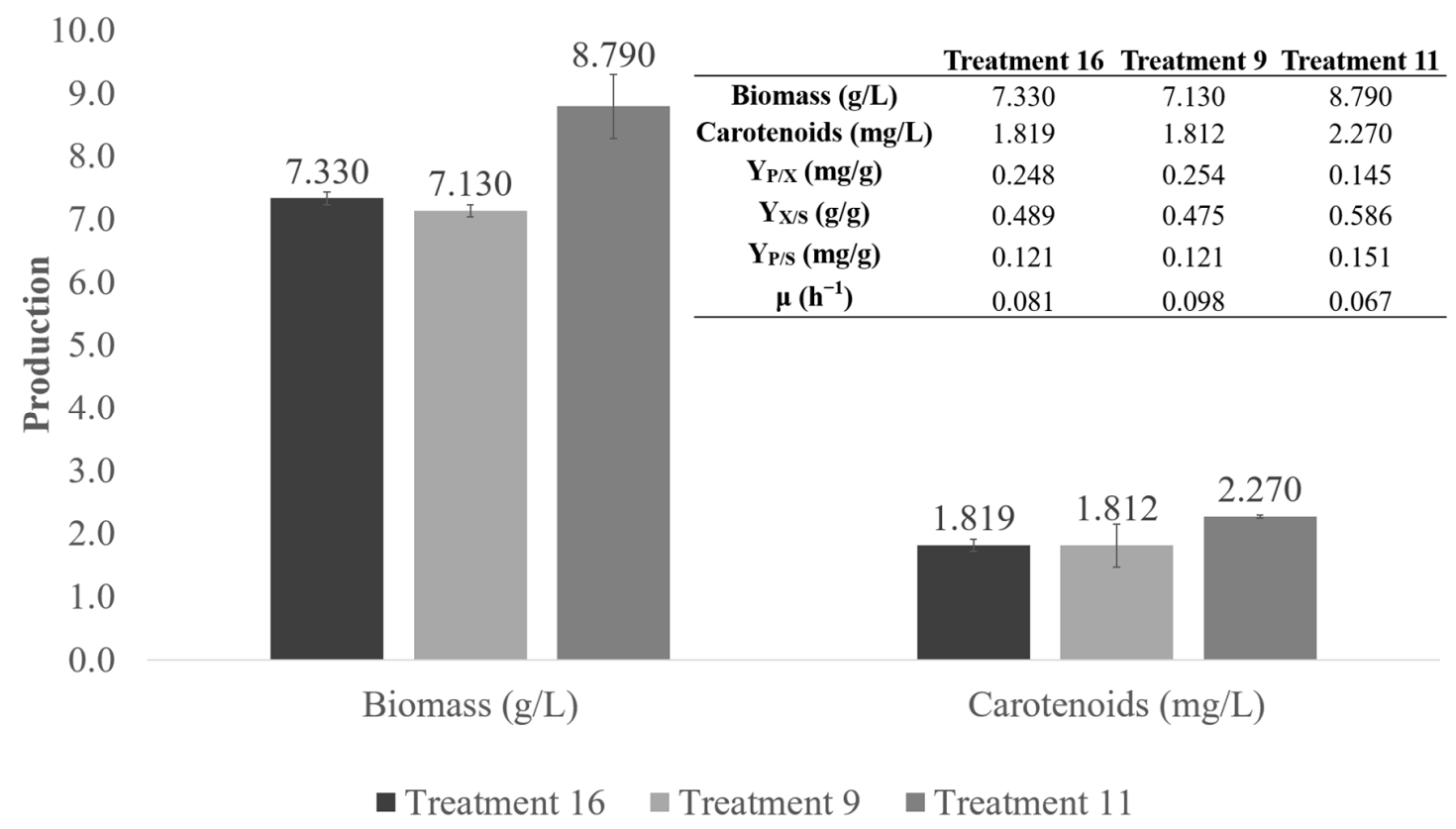

Figure 6. Biomass and total carotenoid production obtained from the comparison of the experimental design of selected treatments 9 and 11 against treatment 16 with high nutrient levels (control) using the yeast $X$. dendrorhous ( $\mu_{\max }$ : maximum specific growth rate).

In treatment 11, the product yield increased, achieving $0.153 \mathrm{mg} / \mathrm{g}$ of substrate compared to the culture medium with high level of nutrients (treatment 16 or control), which obtained a yield of $0.121 \mathrm{mg} / \mathrm{g}$. Treatment 9 produced the same yield as treatment 16 $(0.121 \mathrm{mg} / \mathrm{g}$ of substrate). These results showed the capability of the yeast X. dendrorhous to grow and produce carotenoids in this culture medium, and the need for glutamic acid. It is worth noting that no vitamins were required. The glutamic acid assimilation in the bioreactor was higher compared to the shake flasks, probably because the dissolved oxygen contributed to the aerobic metabolic processes of the glutamic acid on energy generation during the electron transport chain pathway, and the generation of acetyl-CoA for carotenoids and astaxanthin biosynthesis $[9,18,52]$.

Treatment 11 was an efficient, low-complexity culture medium used for carotenoid production in a $110 \mathrm{~L}$ pilot-scale bioreactor (Table 5). The fermentation process was carried out for $120 \mathrm{~h}$, and a biomass growth of $5.65 \mathrm{OD}$ units and carotenoid production of $1.92 \mathrm{mg} / \mathrm{L}$ were observed. The efficiency of the bioprocess and the decrease in the production of carotenoids were probably due to the fact that the kinetic parameters of the process have not been optimized for scaling $[16,20,50,52,53]$. 
Table 5. Comparison of results using an industrial specific culture medium based on treatment 11 at the $2 \mathrm{~L}$ bioreactor level and the $110 \mathrm{~L}$ pilot-scale bioreactor level.

\begin{tabular}{ccc}
\hline & Bioreactor 2 L & Pilot Scale 110 L \\
\hline Biomass $(\mathrm{g} / \mathrm{L})$ & $8.79 \pm 0.50$ & $8.96 \pm 0.10$ \\
Carotenoids $(\mathrm{mg} / \mathrm{L})$ & $2.270 \pm 0.03$ & $1.928 \pm 0.13$ \\
$\mathrm{Y}_{\mathrm{P} / \mathrm{X}}(\mathrm{mg} / \mathrm{g})$ & $0.145 \pm 0.02$ & $0.215 \pm 0.02$ \\
$\mathrm{Y}_{\mathrm{X} / \mathrm{S}}(\mathrm{g} / \mathrm{g})$ & $0.585 \pm 0.03$ & $0.448 \pm 0.01$ \\
$\mathrm{Y}_{\mathrm{P} / \mathrm{S}}(\mathrm{mg} / \mathrm{g})$ & $0.151 \pm 0.01$ & $0.095 \pm 0.01$ \\
$\mu\left(\mathrm{h}^{-1}\right)$ & 0.067 & 0.038 \\
\hline $\mathrm{Y}_{\mathrm{P} / \mathrm{X}}:$ product per biomass yield; $\mathrm{Y}_{\mathrm{P} / \mathrm{S}}:$ product per substrate yield; $\mathrm{Y}_{\mathrm{X} / \mathrm{S}}:$ biomass per substrate yield.
\end{tabular}

Considering the efficient assimilation of the nutrients contained in the culture medium by the yeast, it is possible to explore metabolic engineering strategies to increase the yields of total carotenoids and/or astaxanthin specifically [54-56].

\section{Conclusions}

This study showed that a specific culture medium based on an industrial glucose source (treatment 11; Table 1) without the addition of vitamins has the potential to be used as an alternative to complex culture media such as YM and YPD (containing yeast and malt extracts) in the pigment production by yeast $X$. dendrorhous. The $2^{4}$ experimental design that we carried out revealed that glutamate was the main factor in the specific $\mathrm{CD}$ culture medium for carotenoid production, along with $\mathrm{Na}_{2} \mathrm{HPO}_{4}$. An industrial-grade glucosebased carbon-sourced culture medium allowed us to nearly double the total carotenoid production, probably because of the presence of substrates that contributed to the yeast nutrition. The low-cost culture medium formulated in this study has the advantage of being practical for scaling up to pilot or even industrial levels for carotenoid and astaxanthin production using X. dendrorhous. Moreover, it could be evaluated in the cultivation of other species of yeasts, and costs could be reduced considerably by using food-grade glutamate. However, the carotenoid yield still needs to be improved by means of overproductive strains and/or the implementation of production systems such as a continuous or fed batch to improve biomass.

Supplementary Materials: The following are available online at https:/ /www.mdpi.com/2227-9 717/9/3/429/s1, Figure S1: Disposition of astaxanthin as the major carotenoid produced by $X$. dendrorhous 25-2. (A) Astaxanthin standard curve and (B) final production chromatogram. For this determination, a VARIAN@ProStar 220 HPLC and a VARIAN@ProStar 325 Ultraviolet-Visible detector were used. The mobile phase used was a hexane-acetone mixture in a ratio 82:18 $(v / v)$ at a flow of $1.2 \mathrm{~mL} / \mathrm{min}$. The stationary phase was a Luna Phenomenex®column conditioned at $30^{\circ} \mathrm{C}$.

Author Contributions: Conceptualization, A.T.-H. and M.A.-P.; methodology, A.T.-H., M.A.-P. and E.J.H.-L.; software, A.T.-H.; validation, A.G., M.A.-P. and J.C.M.-D.; formal analysis, R.M.C.-R.; investigation, A.T.-H. and M.A.-P.; resources, M.A.-P. and E.J.H.-L.; data curation, J.C.M.-D.; writingoriginal draft preparation, A.T.-H.; writing-review and editing, M.A.-P. and E.J.H.-L.; visualization, J.C.M.-D.; supervision, M.A.-P.; project administration, M.A.-P.; funding acquisition, M.A.-P. All authors have read and agreed to the published version of the manuscript.

Funding: This work was supported by the CONACYT, CIATEJ, and CASALS company.

Institutional Review Board Statement: Not applicable.

Informed Consent Statement: Not applicable.

Data Availability Statement: Not applicable.

Acknowledgments: This publication is a result of the project "Production, recovery, esterification and encapsulation of astaxanthin produced by Xanthophyllomyces dendrorhous", which was completed through the scholarship assigned by CONACYT (783291) and the CASALS company. 
Conflicts of Interest: The authors declare no conflict of interest. The funders had no role in the design of the study, in the collection, analyses, or interpretation of data, in the writing of the manuscript, or in the decision to publish the results.

\section{References}

1. Avalos, J.; Limón, M.C. Biological roles of fungal carotenoids. Curr Genet. 2015, 61, 309-324. [CrossRef]

2. Ytrestoyl, T.; Bjerkeng, B. Dose response in uptake and deposition of intraperitoneally administered astaxanthin in Atlantic salmon (Salmo salar L.) and Atlantic cod (Gadus morhua L.). Aquaculture 2007, 263, 179-191. [CrossRef]

3. Miao, F.; Lu, D.; Li, Y.; Zeng, M. Characterization of astaxanthin esters in Haematococcus pluvialis by liquid chromatographyatmospheric pressure chemical ionization mass spectrometry. Anal. Biochem. 2006, 352, 176-181. [CrossRef]

4. Chávez-Cabrera, C.; Flores-Bustamante, Z.R.; Flores-Cotera, L.B. Una Vista Integral de la Síntesis de Astaxantina en Phaffia Rhodozyma. World J. Microbiol. Biotechnol. 2010, 14, 24-38.

5. Higuera-Ciapara, I.; Felix-Valenzuela, L.; Goycoolea, F.M. Astaxanthin: A review of its chemistry and applications. Crit. Rev. Food Sci. Nutr. 2006, 46, 185-196. [CrossRef]

6. Xin-Yi, C.; Yi-Jiao, X.; Miao-Miao, Y.; Ming-Jun, Z. Preparation of astaxanthin mask from Phaffia rhodozyma and its evaluation. Process. Biochem. 2019, 79, 195-202. [CrossRef]

7. Domínguez-Bocanegra, A.R.; Ponce-Noyola, T.; Torres-Muñoz, J.A. Astaxanthin production by Phaffia rhodozyma and Haematococcus pluvialis: A comparative study. Appl. Microbiol. Biotechnol. 2007, 75, 783-791. [CrossRef]

8. Boussiba, S.; Vonshak, A.; Cohen, Z.; Richmond, A. Procedure for large-scale production of astaxanthin from Haematococcus. U.S. Patent No. 6,022,701, 8 February 2000. Available online: https://patents.google.com/patent/US6022701A/en (accessed on 12 January 2020).

9. Johnson, E.A. Phaffia rhodozyma: Colorful odyssey. Int. Microbiol. 2003, 6, 169-174. [CrossRef]

10. Amado, I.; Vázquez, J. Mussel processing wastewater: A low-cost substrate for the production of astaxanthin by Xanthophyllomyces dendrorhous. Microb. Cell Fact. 2015, 14, 177. [CrossRef] [PubMed]

11. Mata-Gómez, L.C.; Montañez, J.C.; Méndez-Zavala, A.; Aguilar, C.N. Biotechnological production of carotenoids by yeasts: An overview. Microb. Cell Fact. 2014, 13, 1-11. [CrossRef]

12. Gio-Bin, L.; Sang-Yun, L.; Eun-Kyu, L.; Seung-Joo, H.; Woo-Sick, K. Separation of astaxanthin from red yeast Phaffia rhodozyma by supercritical carbon dioxide extraction. Biochem. Eng. J. 2002, 11, 181-187. [CrossRef]

13. Jyonouchi, H.; Zhang, L.; Gross, M.; Tomita, Y. Immunomodulating actions of carotenoids: Enhancement of in vivo and in vitro antibody production to T-dependent antigens. Nutr. Cancer 1994, 21, 47-58. [CrossRef]

14. Gui-Li, J.; Ling-Yan, Z.; Yu-Tao, W.; Ming-Jun, Z. Astaxanthin from Jerusalem artichoke: Production by fed-batch fermentation using Phaffia rhodozyma and application in cosmetics. Process. Biochem. 2017, 63, 16-25. [CrossRef]

15. Wang, W.; Yu, L. Effects of oxygen supply on growth and carotenoids accumulation by Xanthophyllomyces dendrorhous. Z. Nat. C 2009, 64, 853-858. [CrossRef]

16. Liu, Y.S.; Wu, J.Y. Optimization of cell growth and carotenoid production of Xanthophyllomyces dendrorhous through statistical experiment design. Biochem. Eng. J. 2007, 36, 182-189. [CrossRef]

17. Ramírez, J.; Gutiérrez, H.; Gschaedler, A. Optimization of astaxanthin production by Phaffia rhodozyma through factorial design and response surface methodology. J. Biotechnol. 2001, 88, 259-268. [CrossRef]

18. Meyer, P.S.; du Preez, J.C. Effect of culture conditions on astaxanthin production by a mutant of Phaffia rhodozyma in batch and chemostat culture. Appl. Microbiol. Biotechnol. 1994, 40, 780-785. [CrossRef]

19. Wang, B.; Panc, X.; Jiae, J.; Xiongc, W.; Manirafashac, E.; Lingc, X.; Lu, Y. Strategy and regulatory mechanisms of glutamate feeding to enhance astaxanthin yield in Xanthophyllomyces dendrorhous. Enzym. Microb. Technol. 2019, 125, 45-52. [CrossRef]

20. Schmidt, I.; Schewe, H.; Gassel, S.; Jin, C.; Buckingham, J.; Humbelin, M.; Sandmann, G.; Schrader, J. Biotechnological production of astaxanthin with Phaffia rhodozyma/Xanthophyllomyces dendrohous. Appl. Microbiol. Biotechnol. 2011, 89, 555-571. [CrossRef]

21. Luna-Flores, C.H.; Ramírez-Cordova, J.J.; Pelayo-Ortiz, C.; Femat, R.; Herrera-López, E.J. Batch and fed-batch modeling of carotenoids production by Xanthophyllomyces dendrorhous using Yucca fillifera date juice as substrate. Biochem. Eng. J. 2010, 53, 131-136. [CrossRef]

22. Fang, T.J.; Wang, J.M. Extractability of astaxanthin in a mixed culture of a carotenoid over-producing mutant of Xanthophyllomyces dendrorhous and Bacillus circulans in two-stage batch fermentation. Process. Biochem. 2002, 37, 1235-1245. [CrossRef]

23. Tibayrenc, P.; Preziosi-Belloy, L.; Roger, J.M.; Ghommidh, C. Assessing yeast viability from cell-size measurements? J. Biotechnol. 2010, 149, 74-80. [CrossRef] [PubMed]

24. Máquina, M.; González, N.; Castro, Y. Caracterización fenotípica y genotípica de Rizobios autóctonos provenientes de diversas regiones de Venezuela. Rev. Biol. Trop. 2011, 59, 64-72. Available online: http:/ / www.scielo.sa.cr/scielo.php?script=sci_arttext\& pid=S003477442011000300005\&lng=en\&nr=iso (accessed on 21 September 2019).

25. De la Fuente, J.C.; Oyarzún, B.; Quezada, N.; del Valle, J.M. Solubility of carotenoid pigments (lycopene and astaxanthin) in supercritical carbon dioxide. Fluid Phase Equilib. 2006, 247, 90-95. [CrossRef]

26. Sánchez, A. Monitoreo del estado fisiológico de la levadura Xanthophyllomyces dendrorhous durante la producción de astaxantina por medio de técnicas espectroscópicas y análisis de imágenes. In Tesis de Maestría en Biotecnología Productiva; Centro de 
Investigación y Asistencia en Tecnología y Diseño del Estado de Jalisco: Jalisco, Mexico, 2015; pp. 4-96. Available online: https:/ / ciatej.repositorioinstitucional.mx/jspui/handle/1023/54 (accessed on 30 August 2018).

27. Pan, X.; Ling, X.; Ye, C.; Wu, Y.; Lu, Y. Nitrogen feeding strategies on astaxanthin production by Xanthophyllomyces dendrorhous. J. Xiamen Univ. 2013, 52, 545-552. [CrossRef]

28. Madigan, M.; Martinko, J.; Parker, J. Biología de los Microorganismos, 10th ed.; Editorial Pearson Educación: Madrid, España, 2003; pp. 102-108.

29. Kim, J.H.; Kim, C.W.; Chang, H.I. Screening and characterization of red yeast Xanthophyllomyces dendrorhous mutants. J. Microbiol. Biotechnol. 2004, 14, 570-575. Available online: https:/ / koreauniv.pure.elsevier.com/en/publications/screening-andcharacterization-of-red-yeast-xanthophyllomyces-den (accessed on 5 March 2017).

30. Farías, L.J.; Gschaedler, A.; Sanchez, A.; Cervantes, J.; Arellano, M.; Zamora, C.; Amillastre, E.; Herrera, E.J. Xanthophyllomyces dendrorhous physiological stages determination using combined measurements from dielectric and Raman spectroscopies, a cell counter system and fluorescence flow cytometry. Biochem. Eng. J. 2018, 6, 1-8. [CrossRef]

31. Miller, G.L. Use of Dinitrosalicylic Acid Reagent for Determination of Reducing Sugar. Anal. Chem. 1959, 31, 426-428. [CrossRef]

32. Sedmak, J.; Weerasinghe, D.; Setsuko, J.S. Extraction and quantification of astaxanthin from Phaffia rhodozyma. Biotechnol. Technol. 1990, 4, 107-112. [CrossRef]

33. Bozzo, A.P. Optimización de proceso en Planta Productora de Extracto de Malta, Memoria Para Tener el Título de Ingeniero Civil. Químico; Universidad de Chile Facultad de Ciencias Físicas y Matemáticas, Departamento de Ingeniería Química y Biotecnología: Santiago, Chile, 2012; pp. 4-15. Available online: http:/ / repositorio.uchile.cl/handle/2250/112048 (accessed on 24 October 2018).

34. Phaff, H.J.; Miller, M.W.; Yoneyama, M.; Soneda, M. A comparative study of the yeast florae associated with trees on the Japanese Islands and on the west coast of North America. Fourth Int. Ferment. Symp. 1972, 759-774.

35. Zheng, Y.G.; Hu, Z.C.; Wang, Z.; Shen, Y.C. Large-scale production of astaxanthin by Xanthophyllomyces dendrorhous. Food Bioprod. Process. 2006, 84, 164-166. [CrossRef]

36. Jeong-Hwang, K.; Seong-Woo, K.; Seung-Wook, K.; Hyo-Ihl, C. High-Level Production of Astaxanthin by Xanthophyllomyces dendrorhous Mutant JH1 Using Statistical Experimental Designs. Biosci. Biotech. Bioch. 2005, 69, 1743-1748. [CrossRef]

37. Reynders, M.; Rawlings, D.; Harrison, S. Demonstration of the Crabtree effect in Phaffia rhodozyma during continuous and fed-batch cultivation. Biotechnol. Lett. 1977, 19, 549-552. [CrossRef]

38. Barbachano-Torres, A.; Castelblanco-Matiz, L.M.; Ramos-Valdivia, A.C.; Cerda-García-Rojas, C.M.; Salgado, L.M.; Flores-Ortiz, C.M.; Ponce-Noyola, T. Analysis of proteomic changes in colored mutants of Xanthophyllomyces dendrorhous (Phaffia rhodozyma). Archiv. Microbiol. 2014, 196, 411-421. [CrossRef]

39. Martinez-Moya, P.; Watt, S.A.; Niehaus, K.; Alcaíno, J.; Baeza, M.; Cifuentes, V. Proteomic analysis of the carotenogenic yeast Xanthophyllomyces dendrorhous. BMC Microbiol. 2011, 11, 131. [CrossRef]

40. Clarke, M.A. Chemical and Physical Properties of Corn Syrups. In Encyclopedia of Food Sciences and Nutrition, 2nd ed.; Academic: Cambridge, MA, USA, 2003. Available online: https:/ / www.sciencedirect.com/referencework/9780122270550/encyclopedia-offood-sciences-and-nutrition (accessed on 3 December 2019).

41. Nangia, H.; Hasan, M.; Mohd, A.; Bhatt, P.C.; Panda, B.P. Strain improvement of Phaffia rhodozyma for astaxanthin production. Drug Des. Dev. Ther. 2016, 7, 63-68. [CrossRef]

42. Ramírez, J.; Obledo, N.; Arellano, M.; Herrera, E. Astaxanthin production by Phaffia rhodozyma in a fed-batch culture using a low cost medium feeding. $e$-Gnosis 2006, 4, 1-9. Available online: http:/ / www.redalyc.org/articulo.oa?id=73000405 (accessed on 15 February 2016).

43. An, G.H. Improved growth of the red yeast, Phaffia rhodozyma (Xanthophyllomyces dendrorhous), in the presence of tricarboxylic acid cycle intermediates. Biotechnol. Lett. 2001, 23, 1005-1009. [CrossRef]

44. Yamane, Y.; Higashida, K.; Nakashimada, Y.; Kakizono, T.; Nishio, N. Influence of oxygen and glucose on primary metabolism and astaxanthin production by Phaffia rhodozyma in batch and fed-batch cultures: Kinetic and stoichiometric analysis. Appl. Environ. Microbiol. 1997, 63, 4471-4478. Available online: https:/ /www.ncbi.nlm.nih.gov/pmc/articles/PMC1389289/pdf/hw4471.pdf (accessed on 30 May 2016). [CrossRef]

45. Gill-Hwan, A.; Schuman, D.B.; Johnson, E.A. Isolation of Phaffia rhodozyma mutants with increased astaxanthin content. Appl. Environ. Microbiol. 1989, 55, 116-121. Available online: https://www.ncbi.nlm.nih.gov/pmc/articles/PMC184064/ (accessed on 5 November 2019).

46. Stoklosa, R.G.; Johnston, D.B.; Nghiem, N.P. Phaffia rhodozyma cultivation on structural and non-structural sugars from sweet sorghum for astaxanthin generation. Process. Biochem. 2019, 83, 9-17. [CrossRef]

47. Asadollahi, M.A.; Maury, J.; Patil, K.R.; Schalk, M.; Clark, A.; Nielsen, J. Enhancing sesquiterpene production in Saccharomyces cerevisiae through in silico driven metabolic engineering. Metab. Eng. 2009, 11, 328-334. [CrossRef]

48. Rodríguez-Sáiz, M.; Godio, R.P.; Alvarez, V.; de la Fuente, V.L.; Martín, J.F.; Barredo, J.L. The NADP-dependent glutamate dehydrogenase gene from the astaxanthin producer Xanthophyllomyces dendrorhous: Use of Its promoter for controlled gene expression. Mol. Biotechnol. 2009, 41, 165-172. [CrossRef]

49. Newsholme, P.; Procopio, J.; Ramos, M.; Pithon-Curi, T.; Curi, R. Glutamine and glutamate-their central role in cell metabolism and function. Cell Biochem. Funct. 2003, 21, 1-9. [CrossRef] [PubMed]

50. Johnson, E.A.; Lewis, M.J. Astaxanthin formation by the yeast Phaffia rhodozyma. J. Gen. Microbiol. 1979, 115, 173-183. [CrossRef] 
51. Liu, Z.Q.; Zhang, J.F.; Zheng, Y.G.; Shen, Y.C. Improvement of astaxanthin production by a newly isolated Phaffia rhodozyma mutant with low-energy ion beam implantation. Appl. Microbiol. 2008, 104, 861-872. [CrossRef] [PubMed]

52. Hu, Z.C.; Zheng, Y.G.; Wang, Z.; Shen, Y.C. Production of astaxanthin by Xanthophyllomyces dendrorhous ZJUT46 with fed-batch fermentation in $2.0 \mathrm{~m}^{3}$ fermentation. Food Technol. Biotech. 2007, 45, 209-212. Available online: https://hrcak.srce.hr/file/43787 (accessed on 18 April 2018).

53. Reyes, L.H.; Gomez, J.M.; Kao, K.C. Improving carotenoids production in yeast via adaptive laboratory evolution. Metab. Eng. 2014, 21, 26-33. [CrossRef]

54. Zhang, N.; Li, J.; Li, F.; Wang, S. Selectable marker recycling in the nonconventional yeast Xanthophyllomyces dendrorhous by transient expression of Cre on a genetically unstable vector. Appl. Microbiol. Biotechnol. 2014, 103, 963-971. [CrossRef]

55. Gassel, S.; Schewe, H.; Schmidt, I.; Schrader, J.; Sandmann, G. Multiple improvement of astaxanthin biosynthesis in Xanthophyllomyces dendrorhous by a combination of conventional mutagenesis and metabolic pathway engineering. Biotechnol. Lett. 2013, 35, 565-569. [CrossRef]

56. Zhou, P.; Xie, W.; Li, A.; Wang, F.; Yao, Z.; Biang, Q.; Zhu, Y.; Yu, H.; Ye, L. Alleviation of metabolic bottleneck by combinatorial engineering enhanced astaxanthin synthesis in Saccharomyces cerevisiae. Enzym. Microb. Technol. 2017, 100, 28-36. [CrossRef] [PubMed] 